\title{
Clinical Value of Serum Fibrosis Biomarkers in Prediction of Esophageal Varices in Cirrhotic Patients
}

\author{
GHADA M. GALAL, M.D.; SAFAA KHALAF, M.D. and MARIUM AMIR, M.Sc. \\ The Department of Tropical Medicine and Gastroentrology, Faculty of Medicine, Sohag University
}

\begin{abstract}
Background: Esophageal varices is one of the major complications of portal hypertension, occur in approximately $30 \%-70 \%$ of cirrhotic patients. As portal hypertension is a consequence of liver fibrosis, serum fibrosis biomarkers could serve as non invasive predictors for esophageal varices and their grades.
\end{abstract}

Aim of Study: Determine the frequency and grading of esophageal varices in a group of cirrhotic patients with no history of upper gastrointestinal bleeding, and also evaluate and compare the predictive value of APRI, AAR, FIB-4, FI, and king scores in predicting the presence of varices and their grade.

Patients and Methods: One hundred and one cirrhotic patients were included in the study. The diagnosis of liver cirrhosis was based on clinical, laboratory and ultrasonographic data. An upper GIT endoscopic examination was performed for all patients for the diagnosis of presence or absence of esophageal varices. Serum fibrosis biomarkers were calculated from data available on the first day hospital admission and used as prognostic indicators for presence and grade of esophageal varices.

Results: Patients with esophageal varices had significantly lower mean values of platelet counts and albumin levels than those without esophageal varices ( $p=0.015, p=0.045$; respectively). Also there was a significant difference between patients with and without esophageal varices as regard FI score ( $p=$ $0.016)$. Patients with medium to large esophageal varices had significantly lower mean values of platelet counts than those with no to mild esophageal varices. Also there was a significant difference between patients with medium to large esophageal varices and those with no to mild esophageal varices as regard FI, FI B-4 and King scores $(p=0.003, p=0.001, p=0.017$; respectively). The FI score was accurate in predicting presence of esophageal varices in cirrhotic patients. Using 3.52 cutoff value, a prediction of presence or absence of EV could be made in $62.4 \%$ of cirrhotic patients. FIB-4 (cut off value 3.64), FI (cut off value 3.65) and King (cut off value 26.65) scores may perform better in prediction of high grade esophageal varices than in prediction of presence of esophageal varices.

Correspondence to: Dr. Ghada M. Galal, The Department of Tropical Medicine and Gastroentrology, Faculty of Medicine, Sohag University
Conclusion: Fibrosis index prediction score at cut off value 3.52 is a moderately sensitive noninvasive tool that can predict the presence of esophageal varices in cirrhotic patients with acceptable accuracy. Thus can reduce the burden and make screening for esophageal varices less stressful for the patients. The combination of FI score (cut off value 3.64), FIB-4 score (cut off value 3.65) and King's score (cut off value 26.65) could be used as an initial screening tests to detect patients with high risk EV for whom endoscopy may be more beneficial. Hence the benefit of doing upper endoscopy overweight the burden of this maneuver.

Key Words: Esophageal varices - Serum fibrosis biomarkers - Liver cirrhosis.

\section{Introduction}

LIVER cirrhosis is one of the most common causes of death in the world [1]. Two thirds of all cirrhotic patients develop Esophageal Varices (EV) during their lifetime which is the most frequent cause of severe upper gastrointestinal bleeding [2]. The prognosis gradually worsen with increasing stage of liver cirrhosis [3].

The severity of liver disease as assessed by the Child-Pugh classification significantly affects survival time. The mortality rate for the first episode of bleeding varies from $15 \%$ to $80 \%$ and is higher with Child's class B and C (60\% to $80 \%)$ than with class A (15\%) [4].

Upper gastrointestinal endoscopy is the golden diagnostic test of varices in liver cirrhosis, but because of its invasiveness and discomfort, most of patients are reluctant to undergo this procedure [3] . Recently, numerous non invasive markers for the diagnosis of varices have been explored in patients with liver cirrhosis [5].

Non invasive markers for prediction of varices are primarily derived from non invasive assessment 
of liver fibrosis, like APRI score, which was first developed by Wai and colleagues in 2003 to identify the presence of significant fibrosis and liver cirrhosis in patients with chronic hepatitis $\mathrm{C}$ [6] Similarly, AAR, FIB-4, FI, and King scores were originally used for the assessment of liver fibrosis and its severity in patients with hepatitis $C$ [7]

\section{Aim of the work:}

To determine the frequency of esophageal varices in a group of cirrhotic patients with no history of upper gastrointestinal bleeding, and also evaluate and compare role of APRI, AAR, FIB-4, FI, and King scores in predicting the presence of varices and their grade.

\section{Patients and Methods}

\section{Patients:}

This study was a prospective study conducted at the Department of Tropical Medicine and Gastroenterology, Sohag University Hospital from October 2016 to September 2017. The study protocol was approved by Sohage Faculty of Medicine Ethical Committee. One hundred and one cirrhotic patients were included in the study. The diagnosis of liver cirrhosis was based on clinical, laboratory and ultrasonographic data. An upper Gastrointestinal Endoscopic examination was performed for all patients for the diagnosis of presence or absence of esophageal varices and their grade. A written informed consent was obtained from all participants before inclusion in the study.

\section{Exclusion criteria:}

1- Patients with previous diagnosis of esophageal varices who underwent band ligation or sclerotherapy.

2- Patients who underwent splenectomy.

3- Patients with previous diagnosis of bleeding peptic ulcer.

4- Patients who refused upper gastrointestinal endoscopic examination.

5- The patients with missing relevant laboratory data.

6- Patients with portal vein thrombosis.

\section{Methods:}

Routine laboratory investigations: A venous blood sample of $10 \mathrm{ml}$ was obtained from each patient, EDTA samples were subjected to complete blood count on cell Dyne-2700 fully automated cell counter. The Na-citrated samples were used for determination of PT and concentration on SYSMEX fully automated system. Renal function tests and liver function tests were performed by Beckman SYNCHRON CX9 fully automated chemical auto analyzer.

Esophagogastroduodenoscopy: Complete endoscopic examination using a video endoscope (videoscope Olympus GIF-XQ 260) was done for all the patients. Informed written consent was pretaken from every patient. Endoscopic examination was performed without knowledge of the patient's blood samples data. All patients were examined by a single endoscopist and the grade of EV was classified into F0, F1, F2, F3 according to Japanese classification [8]. Based on the endoscopic results patients were grouped as having no to small (F0, F1) and medium to large (F2, F3) EV.

Predictive scores: Liver prognostic indicators were calculated from data available on the first day of hospital admission.

- Model for End-stage Liver Disease (MELD) score [9].

- The APRI score was calculated using Wai's formula [6]:

$$
\frac{\text { (AST/upper limit of normal) }}{\text { Platelet count (expressed as platelets X } \left.10^{9} / \mathrm{L}\right)} \times 100
$$

- The FIB-4 score was calculated using Sterling's formula [10] as:

$$
\begin{gathered}
\text { Age (y) X AST (IU/l) } \\
\text { Platelet count (X } 10^{9} / \text { liter) }
\end{gathered}
$$

- AAR was calculated as: (AST/ALT) [11]

- Fibrosis Index (FI) was calculated as: (8-0.01 X PLT-ALB) [12] .

- King score was calculated as: (Age X AST X INR/PLT) [7].

\section{Statistical analysis:}

Data were analyzed using SPSS Version 16. Quantitative data were represented as mean \pm standard deviation and qualitative data were presented as number and percentage. Data were analyzed using student $t$-test to compare means of two groups. When the data were not normally distributed Mann-Whitney test was used to compare two groups. Graphs were produced by using Excel. $p$ value was considered significant if it was less than 0.05. Receiver Operating Characteristics (ROC) curve: Was used to detect sensitivity, specificity, cut-off point, PPV and NPV. 


\section{Results}

Among 101 cirrhotic patients, 63 of them were males and 38 were females. The mean age of all patients was $53.6 \pm 11$ years. The patients' demographic and ultrasonographic findings are summarized in (Table 1). Sixty five (64\%) of the studied patients had esophageal varices Fig. (1). Most of them had small EV Fig. (2).

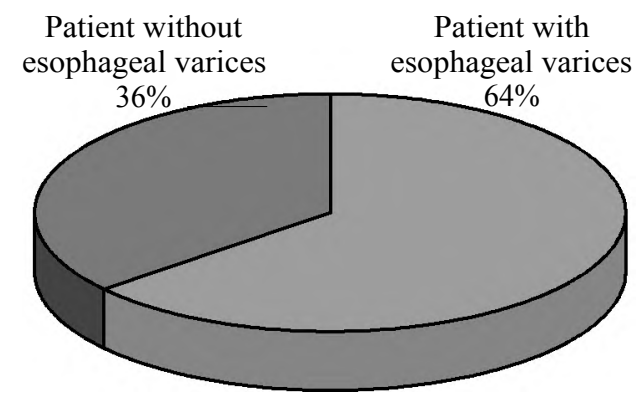

Fig. (1): Presence of esophageal varices among the studied patients.

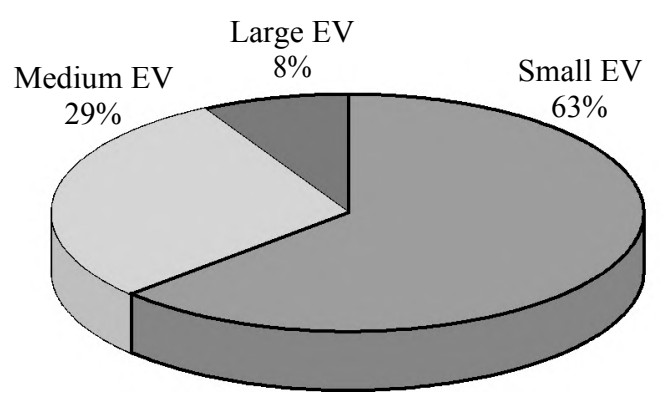

Fig. (2): Distribution of EV grades among studied patients.

Patients with EV had significantly lower mean values of albumin $(2.95 \pm 0.75$ versus $3.29 \pm 0.9)$ and platelet $(115 \pm 69.52$ versus $145 \pm 57.39)$ than those without $\mathrm{EV}$ ( $p=0.045, p=0.015$; respectively). Regarding fibrosis biomarkers FI score superior to the other scores in predilection of EV. There was a significant difference in mean value of FI score between patients with esophageal varices (3.86 \pm 1.16 cut-off value) and those without $(3.33 \pm 0.9$ cut-off value) $(p=0.018)$.

Hemoglobin level, serum bilirubin level, international normalization ratio, FIB-4 score, King score, MELD score, APRI score and AAR didn't show significant difference between patients with EV and patients without EV (Table 2).

\section{In patients with $E V$ :}

Patients with medium to large EV had significantly lower mean values of platelet than those with no to mild EV ( $p=0.001)$. There was a significant difference between those with no to mild EV and others with medium to large EV regarding Fibrosis Index, FIB-4 and King scores $(p=0.003$, $p=0.002, p=0.017$; respectively). FI score cut-off value $\geq 4.14 \pm 0.9$, FIB- 4 score cut-off value $\geq 7.78 \pm$ 5.4 and King score cut-off value $\geq 55.24 \pm 39.64$ were significantly associated with the presence of high grade EV (Table 2).

ROC curve analysis of different scores in prediction of presence and grade of $\mathrm{EV}$ in cirrhotic patients Figs. (2,3): As regard prediction of presence of EV: FI score had AUC $=0.65$ with $63 \%$ sensitivity, $62 \%$ specificity and $62.4 \%$ accuracy (Table 3). As regard prediction of grade of EV: FIB-4 score had the largest AUC (AUC $=0.70)$, followed by FI score (AUC $=0.69)$, KING score (AUC $=0.65$ ), AUC of FIB-4 score was significantly different from other scores in predicting the presence of EV $(p=0.001)$ (Table 4).

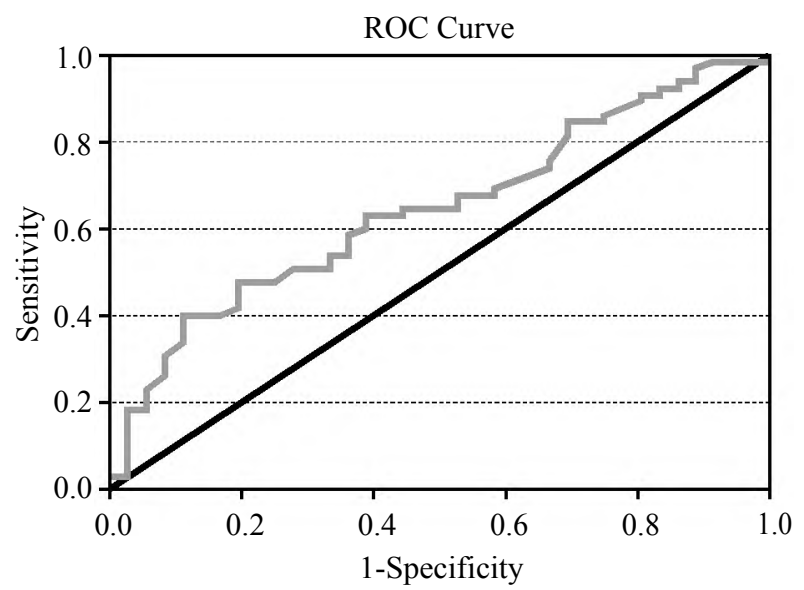

Fig. (3): Performance of Receiver Operating Curve (ROC) of FI score in prediction of presence of $\mathrm{EV}$ in cirrhotic patients.
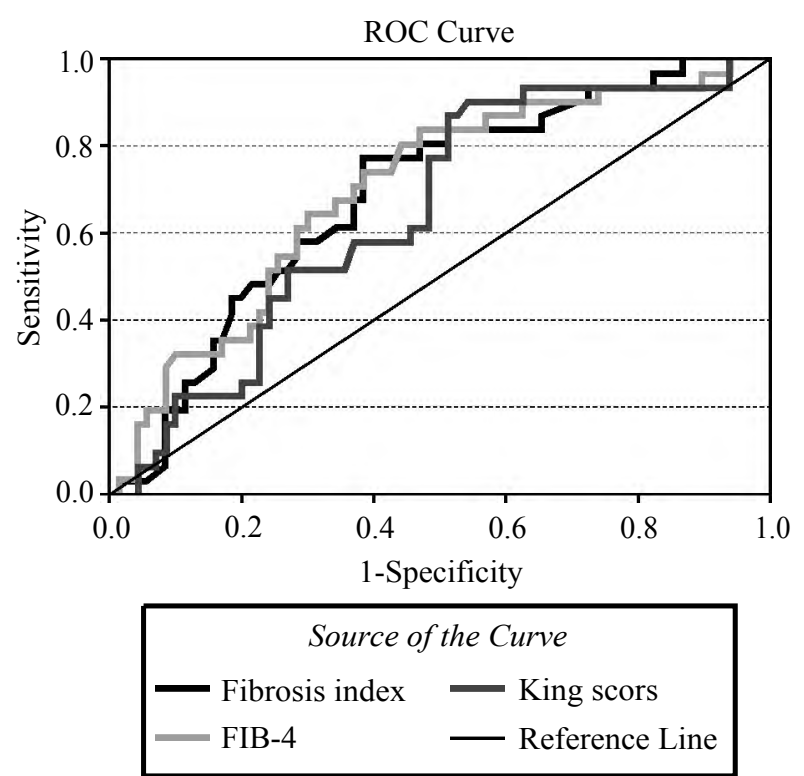

Fig. (4): Comparison of Receiver Operating Curves (ROC) of different scores in prediction of high grades EV in cirrhotic patients. 
Table (1): Demographic and sonographic data of the studied patients.

\begin{tabular}{lccc}
\hline Characteristics & $\begin{array}{c}\text { All patients } \\
\text { Summary statistics } \\
\mathrm{N}=101\end{array}$ & $\begin{array}{c}\text { Patients with EV } \\
\text { Summary statistics } \\
\mathrm{N}=65\end{array}$ & $\begin{array}{c}\text { Patients without EV } \\
\text { Summary statistics } \\
\mathrm{N}=36\end{array}$ \\
\hline Age & $53.67 \pm 11.003$ & $53.4 \pm 11.52$ & $10.1 \pm 1.69$ \\
Sex: & $63(62.4 \%)$ & $41(63.1 \%)$ & $22(61.1 \%)$ \\
Male & $38(37.6 \%)$ & $24(26.9 \%)$ & $14(38.9)$ \\
Female & & & \\
Splenic size: & $36(35.6 \%)$ & $20(30.8 \%)$ & $16(44.4 \%)$ \\
Average & $65(64.4 \%)$ & $45(69.2 \%)$ & $20(55.6 \%)$ \\
Enlarged & & & \\
Liver size: & $12(11.9 \%)$ & $10(15.4 \%)$ & $2(5.6 \%)$ \\
Shrunken & $70(69.3 \%)$ & $45(69.2 \%)$ & $25(69.4 \%)$ \\
Average & $19(18.8 \%)$ & $10(15.4 \%)$ & $9(25 \%)$ \\
Enlarged & & & \\
Portal vein diameter: & $82(81.2 \%)$ & $50(76.9 \%)$ & $32(88.9 \%)$ \\
Average & $19(18.2 \%)$ & $15(23.1 \%)$ & $4(11.1 \%)$ \\
Dilated & & & \\
Ascites: & $71(70.3 \%)$ & $42(64.6 \%)$ & $29(80.6 \%)$ \\
No & $13(12.9 \%)$ & $11(16.9 \%)$ & $2(5.6 \%)$ \\
Mild & $7(6.9 \%)$ & $4(6.2 \%)$ & $3(8.3 \%)$ \\
Moderate & $10(9.9 \%)$ & $8(12.3 \%)$ & $2(5.6 \%)$ \\
Marked & & &
\end{tabular}

Table (2): Comparing laboratory findings in the studied patients as regard presence of esophageal varices and their grades.

\begin{tabular}{lllllll}
\hline & $\begin{array}{c}\text { Patients } \\
\text { without EV } \\
\mathrm{N}=36(36 \%)\end{array}$ & $\begin{array}{c}\text { Patients } \\
\text { with EV } \\
\mathrm{N}=65(64 \%)\end{array}$ & $\begin{array}{c}p \text { - } \\
\text { value }\end{array}$ & $\begin{array}{c}\text { Patients with } \\
\text { no to small EV } \\
\mathrm{N}=69(68 \%)\end{array}$ & $\begin{array}{c}\text { Patients with medium } \\
\text { to large EV } \\
\mathrm{N}=32(32 \%)\end{array}$ & $\begin{array}{c}p \text { - } \\
\text { value }\end{array}$ \\
\hline Albumin (g/dl) & $3.29 \pm 0.9$ & $2.95 \pm 0.75$ & 0.045 & $3.15 \pm 0.85$ & $2.9 \pm 0.74$ & 0.14 \\
Platelets (X10 $)$ & $145 \pm 57.39$ & $115 \pm 69.52$ & 0.015 & $139 \pm 71.22$ & $92.85 \pm 39.34$ & 0.001 \\
T.Bilirubin (mg/dl) & $2.26 \pm 3.5$ & $1.96 \pm 2.2$ & 0.608 & $2.24 \pm 2.98$ & $1.69 \pm 2.05$ & 0.29 \\
INR & $1.22 \pm 0.25$ & $1.32 \pm 0.3$ & 0.078 & $1.27 \pm 0.31$ & $1.3 \pm 0.23$ & 0.54 \\
Hb (gm/dl) & $11.61 \pm 2.36$ & $10.99 \pm 2.16$ & 0.184 & $11.39 \pm 2.35$ & $10.8 \pm 1.97$ & 0.19 \\
FI score & $3.33 \pm 0.99$ & $3.86 \pm 1.16$ & 0.016 & $3.44 \pm 1.16$ & $4.14 \pm 0.9$ & 0.003 \\
FIB-4 score & $5.95 \pm 6.95$ & $6.25 \pm 4.79$ & 0.801 & $5.38 \pm 5.61$ & $7.78 \pm 5.38$ & 0.001 \\
King score & $51.9 \pm 67.37$ & $47.47 \pm 40.78$ & 0.681 & $46.18 \pm 56.26$ & $55.24 \pm 39.64$ & 0.017 \\
MELD score & $10.72 \pm 4.92$ & $11.8 \pm 4$ & 0.235 & $11.39 \pm 4.79$ & $11.47 \pm 3.37$ & 0.9 \\
APRI score & $2.03 \pm 2.03$ & $1.64 \pm 1.28$ & 0.241 & $1.73 \pm 1.73$ & $1.88 \pm 1.24$ & 0.64 \\
AAR score & $1.61 \pm 1.73$ & $1.47 \pm 0.71$ & 0.572 & $1.53 \pm 1.31$ & $1.5 \pm 0.82$ & 0.9 \\
\hline Hb : Hemoglobin. & \multicolumn{7}{c}{ T. $:$ Total. } \\
INR: International Normalized Ratio. & \multicolumn{3}{c}{ EV : Esophageal Varices. } & &
\end{tabular}

Table (3): Performance of ROC for FI score in prediction of presence of EV in cirrhotic patients.

\begin{tabular}{lccccccc}
\hline Score & Cut off & AUC & Sensitivity & Specificity & PPV & NPV & Accuracy \\
\hline FI & $>3.52$ & 0.65 & $63.1 \%$ & $62 \%$ & $74.5 \%$ & $48 \%$ & $62.4 \%$ \\
\hline
\end{tabular}

Table (4): AUC, sensitivity, specificity, positive and negative predictive values (percentages) and significance of different scores for prediction of medium to large esophageal varices in cirrhotic patients.

\begin{tabular}{llccccccc}
\hline Score & Cut off & AUC & $p$-value & Sensitivity & Specificity & PPV & NPV & Accuracy \\
\hline FIB-4 & $>3.65$ & 0.70 & 0.001 & $84 \%$ & $53 \%$ & $44 \%$ & $88 \%$ & $62 \%$ \\
FI & $>3.64$ & 0.69 & 0.004 & $77 \%$ & $61.4 \%$ & $43.6 \%$ & $85 \%$ & $62.4 \%$ \\
KING & $>26.65$ & 0.65 & 0.016 & $77 \%$ & $52 \%$ & $40.6 \%$ & $83.7 \%$ & $59 \%$ \\
\hline
\end{tabular}




\section{Discussion}

Patients with liver cirrhosis frequently require screening endoscopy for varices so that prophylactic therapy or follow-up can be planned for them. It is unclear how often patients should be screened by endoscopy for varices [13]. The estimated prevalence of esophageal varices in patients with cirrhosis ranges from $30 \%$ to $80 \%$ [14]. The risk of hemorrhage is $25 \%$ to $35 \%$ over a period of 2 years [15]. The authoritative guidelines establish that patients with medium or large varices found on screening endoscopy should receive prophylactic medical or endoscopic variceal band ligation [16] This highlights the importance of the ability to predict which patients have the highest possibility of large esophageal varices and should undergo screening endoscopy.

In the current study, we found that about two third (64\%) of our patients had esophageal varices on endoscopy. Similar results were reported by Sheta et al., [17]. Among patients with varices $(n=$ $65)$ the majority of them (62\%) show small varices. Medium varices were found in $29 \%$, and large varices in $8 \%$. This agrees with Ravi et al., [18] where most of the reported EV were small. Also, we reported the presence of medium and large varices in $32 \%$ of all studied patients. This high prevalence justifies the importance of endoscopic screening in cirrhotic patients as these varices are at risk of bleeding and need prophylactic measures.

Approximately $4-30 \%$ of patients with small varices will turn to large varices each year and will therefore be at risk of bleeding [19]. In the first two years after detection of esophageal varices, the risk of esophageal bleeding ranges from 20$30 \%$ and the one week mortality reaches $30 \%$ [20,21]

Generalized screening program of periodical esophagogastrodudenoscopy in patients with liver cirrhosis may lead to high cost and low compliance, as unfortunately, endoscopy is invasive, uncomfortable, expensive, and time consuming and frequently requires sedation and may be poorly accepted by many patients if repeatedly required. Prediction of esophageal varices by non invasive methods are perceived by patients as preferable to endoscopy and thus might increase compliance and adherence to screening programs and restrict the performance of endoscopy to those patients with a high probability of having varices [22]

In this study, we evaluated the effectiveness of serum fibrosis biomarkers in predicting the presence and grade of esophageal varices in cirrhotic patients admitted to our hospital with no history of previous gastrointestinal bleeding. Among the 101 cirrhotic patients, $63(62.4 \%)$ of them were males which means the predominance of cirrhosis among males. This comes together with other studies of Rogers and his colleagues [23], who found that men are 2 fold more likely to be affected by chronic liver disease and cirrhosis than women.

We found that low platelet counts and serum albumin levels had statistically significant association with the presence of esophageal varices in cirrhotic patients. These findings are in accordance with many other studies, that revealed a significant difference between patients with and those without $\mathrm{EV}$ as regard serum albumin level and platelet count [3,24-26]. Also, in Egyptian study conducted by Ayman and his colleagues [27] on 120 cirrhotic patients found that low serum albumin is significantly associated with presence of varices. In addition, we found that platelet count was significant predictors for high grade EV in cirrhotic patients, as patients with medium to large EV had significantly lower mean values of platelet counts than those with no to small EV. These findings are also in accordance with previous studies $[3,25]$.

Also our results were in line with those reported by Said et al., [28], Giannini et al., [29] found that platelet count of less than 100000 can be used as a predictor of $\mathrm{EV}$ and the more decrease in platelet count the greater is the risk of having esophageal varices.

Hence no debates had been found about the value of platelet counts and albumin levels as significant predictors of $\mathrm{EV}$ in patient with liver cirrhosis and the validation of their clinical utility had been proven in many previous studies. To amplify this difference in serum albumin and platelet values among cirrhotic patients for prediction of presence or absence of esophageal varices in patients screened by upper endoscopy, an index, called the Fibrosis Index (FI) developed by Ota et al., [12] had been used.

In the present study, we found that cirrhotic patients with EV had significantly higher FI value than those without EV. So, FI score can be used as a significant predictor for presence of $\mathrm{EV}$ in cirrhotic patients. These findings are in accordance with those of Deng et al., [3] who reported that significantly higher FI score was found in esophageal varices group compared to no esophageal varices group. But we disagreed with this study in that there is no statistically significant difference in mean value of FIB-4 score between the two groups. 
In current study, we found cirrhotic patients with medium to large EV had significantly higher FI score than those with no to small EV. This was in agreement with the previous study [3]. Also, cirrhotic patients with medium and large EV had higher FIB-4 score values than those with no to small EV, so FI and FIB-4 scores can be used as a significant predictor for the grade of EV in cirrhotic patients. This comes together with Deng et al., who showed that FIB-4 score can be used as a significant predictor for grading of EV [3] .

King score, MELD score, APRI score and AAR score couldn't be used as predictors for the presence or the grade of esophageal varices in cirrhotic patients. These findings are also in accordance with Deng et al., [3] who found that, there was no significant difference between cirrhotic patients with and those without EV and also between patients with different grades of EV.

Many previous studies investigating FIB-4 as a predictor of $\mathrm{EV}$ in cirrhotic patients showed statistically significant results. Taking a cut-off value of 2.8-3.98, the AUC predicting the presence of EV ranged from $62 \%$ to $78 \%$. However, their sensitivities and specificities were relatively low, ranging from $66 \%$ to $76 \%$ and from $54 \%$ to $80 \%$, respectively $[\mathbf{3 , 3 0 - 3 3 ]}$. On the other hand in our study, FI was superior to FIB-4 in prediction of EV. At a cut-off value of 3.52 with good accuracy $62 \%$, sensitivity $63 \%$, specificity $62 \%$, PPV $74.5 \%$, and the AUC was $65 \%$. Thus could be accepted as a beneficial initial screening test.

Although the accuracy of serum biomarkers in the detection of small varices is suboptimal, it is very good in detection of large varices and could be useful in patients not willing to undergo upper endoscopy [34] .

According to Receiver Operating Curves (ROC) FIB-4 (at cut off >3.65) and FI (at cut off >3.64) scores had an AUC for prediction of grade of EV in cirrhotic patients $70 \%$ and $69 \%$ respectively. Thus FIB-4 score was superior to FI score in prediction of high grade varices. FIB-4 score at cut off value more than 3.65 had sensitivity about $84 \%$, specificity $53 \%$ and accuracy $62 \%$ in prediction of medium and large EV, and at cut off value less than 3.65 can perfectly role out the presence of high grade varices in $88 \%$ of the patients (NPV= $88 \%$ ). Deng and his colleagues [3] used FIB-4 score with cut off $>4.41$ and showed $69 \%$ AUC, with $87.72 \%$ sensitivity and $50.91 \%$ specificity. They also used FI score at cut off $>-26.75$ and showed $66 \%$ AUC, $54 \%$ sensitivity and $73 \%$ specificity.
However, according to our research, we found that FI score (using cut off >3.64) had $77 \%$ sensitivity, $61 \%$ specificity and $62 \%$ accuracy. Many studies on use of serum fibrosis biomarkers in prediction of presence and grade of EV in cirrhotic patients have been published in the past few years, but no one studied the value of FI score as a serum biomarker for predilection of EV in cirrhotic patient according to the meta-analysis done by Deng and his colleagues [35] till that study done in 2015 by Deng et al., [3] .

Our study has several unique features. First, we recruited consecutive patients undergoing screening upper gastrointestinal endoscopy at our endoscopy unit who met the inclusion criteria. Secondly, all patients included had no history of previous attacks of upper gastrointestinal tract bleeding or underwent splenectomy. Many prior studies didn't have these features [3], which may have introduced selection bias. Thirdly, our study included a sufficient proportion of patients with esophageal varices $(64.4 \%)$.

\section{Conclusion:}

Fibrosis index prediction score at cut off value 3.52 is a moderately sensitive noninvasive tool that can predict the presence of EV in cirrhotic patients with acceptable accuracy. Thus can reduce the burden and make screening for varices less stressful for the patients.

The combination of FI score (cut off value 3.64), FIB-4 score (cut off value 3.65) and King's score (cut off value 26.65) could be used as an initial screening tests to detect patients with high risk EV for whom endoscopy may be more beneficial. Hence the benefit of doing upper endoscopy overweight the burden of this maneuver.

\section{References}

1- HARRISON P.M.: Management of patients with decompensated cirrhosis. Clin. Med., 15 (2): 201-3, 2015.

2- GARCEAU A.J. and CHALMERS T.C.: Boston Interhospital Liver Group: Natural history of cirrhosis. Survival with esophageal varices; N. Engl. J. Med., 268: 469-73, 1963.

3- DENG H., QI X., PENG Y., LI J., LI H., ZHANG Y., LIU X., SUN X. and GUO X.: Diagnostic Accuracy of APRI, AAR, FIB-4, FI, and King Scores for Diagnosis of Esophageal Varices in Liver Cirrhosis. Med. Sci. Monit., 21: 3961-77, 2015.

4- CAREY W.D.: Predictors of variceal bleeding: Solving the puzzle. Am. J. Gastroenterol., 85: 1426-7, 1990.

5- KIM M.Y., JEONG W.K. and BAIK S.K.: Invasive and non-invasive diagnosis of cirrhosis and portal hypertension. World J. Gastroenterol., 20: 4300-15, 2014. 
6- WAI C.T., GREENSON J.K., FONTANA R.J., KAIBFLEEISCH J.D. and MARRERO J.A.: A simple noninvasive index can predict both significant fibrosis and cirrhosis in patients with chronic hepatitis C. Hepatology, 38: 51826, 2003.

7- CROSS T.J., RIZZI P., BERRY P.A., BRUCE M., PORTMANN B. and HARRISON P.M.: King's Score: An accurate marker of cirrhosisinchronic hepatitis C. Eur. J. Gastroenterol. Hepatol., 21: 730-8, 2009.

8- Japanese Research Society for Portal Hypertension: The general rules for recording endoscopic findings on esophageal varices. Jpn. J. Surg., 10 (1): 84-7, 1980.

9- KAMATH P.S. and KIM W.R.: The model for end-stage liver disease (MELD). Hepatology, 45: 797-805, 2007.

10- STERLING R.K., LISSEN E., CLUMECK N., SOLA R., CORREA M.C., MONTANER J., SULKOWSKI S.M., TORRIANI F.J., DIETERICH D.T., THOMAS D.L., MESSINGER D. and NELSON M.: Development of a simple noninvasive index to predict significant fibrosis in patients with HIV/HCV coinfection. Hepatology; 43: 1317-25, 2006.

11- GIANNINI E., RISSO D., BOTTA F. CHIARBONELLO B., FASOLI A., MALFATTI F., ROMAGNOLI P., TESTA E., CEPPA P. and TESTA R.: Validity and clinical utility of the aspartate aminotransferase-alanine aminotransferase ratio in assessing disease severity and prognosis in patients with hepatitis $\mathrm{C}$ virus-related chronic liver disease. Arch. Intern. Med., 163: 218-24, 2003.

12- OHTA T., SAKAGUCHI K., FUJIWARA A., FUJIOKA S., IWASAKI Y., MAKINO Y., ARAKI Y. and SHIRATORI Y.: Simple surrogate index of the fibrosis stage in chronic hepatitis $\mathrm{C}$ patients using platelet count and serum albumin level. Acta Med. Okayama, 60 (2): 77-84, 2006.

13- MADHOTRA R., MULCAHY H.E., WILLNER I. and REUBEN A.: Prediction of esophageal varices in patients with cirrhosis. J. Clin. Gastroenterol., 34 (1): 81-5, 2002.

14- LAY C.S., TSAI Y.T., TEG C., SHYU W.S., GUO W.S., WU K.L. and LO K.J.: Endoscopic variceal prophylaxis of first variceal bleeding in cirrhotic patients withhighrisk esophageal varices. Hepatology, 25: 1346-50, 1997.

15- POYNARD T., CALES P., PASTA L., IDEO G., PASCAL J.P., PAGLIARO L. and LEBREC D.: Beta-adrenergic antagonist drugs in the prevention of gastrointestinalbleeding in patients with cirrhosis and esophageal varices. An analysis ofdata and prognostic factors in 589 patients from four randomized clinicaltrials. Franco-Italian Multicenter Study Group. N. Engl. J. Med., 324: 1532-38, 1991.

16- De FRANCHIS R.: Updating consensus in portal hypertension: Report of theBaveno III consensus workshop on definitions, methodology, and thera-peutic strategies in portal hypertension. J. Hepatol., 33: 846-52, 2000.

17- SHETA E.A., YOUSEF M., ABD-ELSALAM S., ESSAMELDEEN R., ISMAIL A., EL-KALLA F., MANSOUR L., KOBTAN A., ELHENDAWY M. and ELSABAGH H.M.: Non Invasive Diagnosis of Esophageal Varices: Can it Replace Screening Endoscopy? Int. J. Curr. Microbiol. App. Sci., 5 (5): 701-5, 2016.

18-RAVI M., HUGH M., IRA W. and ADRIAN R.: Prediction of Esophageal Varices in Patients With Cirrhosis. Journal of Clinical Gastroenterology, 34 (1): 81-5, 2002.
19- DTTE P., LABRECQUE D., FRTED M., GANGL A., KHAN G.A., BJORKMAN D., ELIAKIM R., BEKTAEVA R., SARIN S.K., FEDAIL S., KRABSHUS J.H. and LE MAIR A.: Esophageal varices. World Gastroenterology Organisation practice guideline: June, 2008.

20- CALES P., DESMORAT H., VINGEL J.P., CAUCANAS J.P., RAVAUD A., GERIN P., BROUET P. and PASCAL J.: Incidence of large varices in patients with cirrhosis: Application to prophylaxis of first bleeding. Gut., 31 (11): 1298-302, 1990.

21- D'AMICO G. and LUCA A.: Portal hypertension. Natural history. Clinical-hemodynamic correlations. Prediction of the risk of bleeding. Bailliers Clin. Gastroenterol., 11: 243-56, 1997.

22- De FRANCHIS R.: Non-invasive (and minimally invasive) diagnosis of oesophageal varices. Journal of Hepatology, 49 (4): 520-7, 2008.

23- ROGERS R.G., EVERETT B.G., SAINT ONGE J.M. and KRUEGER P.M.: Social, behavioral, and biological factors, and sex differences in mortality. Demography, 3 : 555-78, 2010.

24- ZEIN C.O., LINDOR K.D. and ANGULO P.: Prevalence and Predictors of Esophageal Varices in Patients With Primary Sclerosing Cholangitis. Hepatology, 39: 204-10, 2004.

25- SALEM M.N., ELHAWARY M.A., MOHAMED M.G., KHEDR M.A. and ABDALLAH S.R.: Role of Right Liver Lobe Diameter/Serum Albumin Ratio in Esophageal Varices Assessment. The Egyptian Journal of Hospital Medicine, 73 (7): 7112-8, 2018.

26- ADEL A.M. and GEORGE S.R.: A novel non-invasive Ratio for oesophageal varices prediction in HCV-liver cirrhosis Egyptian patients. Journal of American Science, 7 (11): 33-6, 2011.

27- AYMAN Y., RBAB F., MOHAMAD A.B., et al.: Non Invasive Prediction of Varices in Egyptian Cirrhotic Patients, Med. J. Cairo Univ., 77 (1): 343-9, 2009.

28- SAID H.E., ELSAYED E.Y., AMEEN A. and ABD ELAL H.: Cytopenia as a predictor ofoesophageal varices in patients with liver cirrhosis. Rep. Opin., 2: 35-41, 2010.

29- GIANNINI E., BOTTA F., BORRO P., RISSO D., ROMAGNOLI P., FASOLI A., MELE M.R., TESTA E., MANSI C., SAVARINO V. and TESTA R.: Platelet count/ spleen diameter ratio: Proposal and validation of a noninvasiveparameter to predict the presence of oesophagealvarices in patientswith liver cirrhosis. Gut., 52: 1200-5, 2003.

30- SEBASTIANI G., TEMPESTA D., FATTOVICH G., CASTERA L., HALFON P., BOURLIERE M., NOVENTA F., ANGELI P., SAGGIORO A. and ALBERTI A.: Prediction of oesophageal varices in hepatic cirrhosis by simple serum non-invasive markers: Results of a multicenter, large-scale study. J. Hepatol., 53: 630-8, 2010.

31- STEFANESCU H., GRIGORESCU M., LUPSOR M., MANIU A., CRISAN D., PROCOPET B., FEIER D. and BADEA R.: A new and simple algorithm for the noninvasive assessment of esophageal varices in cirrhotic patients using serum fibrosis markers and transient elastography. J. Gastrointestin Liver Dis., 20: 57-64, 2011. 
32- HAS SAN E.M., OMRAN D.A., El BESHLAWEY M.L., ABDO M. and EL ASKARY A.: Can transient elastography, Fib-4, Forns Index, and Lok Score predict esophageal varices in HCV-related cirrhotic patients? Gastroenterol. Hepatol., 37: 58-65, 2014.

33- KRAJA B., MONE I., AKSHIJA I., KOCOLLARI A., PRIFTI S. and BURAZERI G.: Predictors of esophageal varices and first variceal bleeding in liver cirrhosis patients World J. Gastroenterol., 23 (26): 4806-14, 2017.

34- DENG H., QI X. and GUO X.: Diagnostic Accuracy of APRI, AAR, FIB-4, FI, King, Lok,Forns, and FibroIndex Scores in Predictingthe Presence of Esophageal Varices in Liver Cirrhosis A Systematic Review and MetaAnalysis. Medicine, 94 (42): e1795.

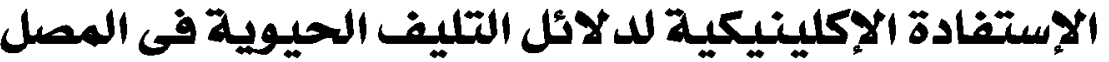

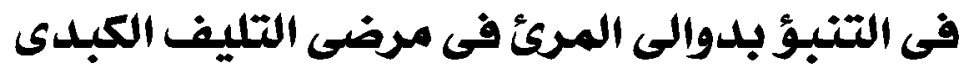

التليف الكبدى يسبب العديد من المضاعفات بسبب إرتفاع ضفط الدم بالوريد البابي. وحدوث دوالى بالمرئ هو آكبر المضاعفات التى يمكن آن تحدث فى . V\% من مرضى التلف الكبدى وكان الهدف من هذه الدراسة المستقبلية هو تحديد الإستفادة الإكلينيكية APRI, AAR, FIB-4, MELD and King scores J

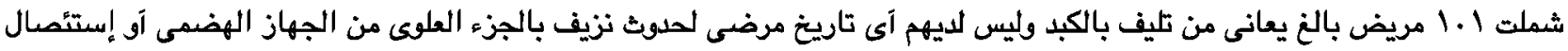

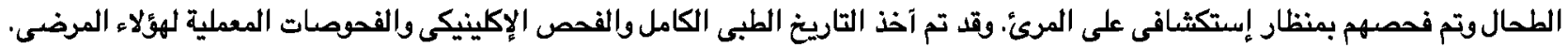

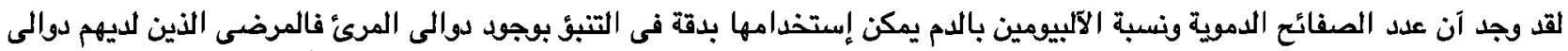

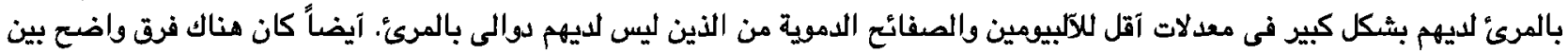

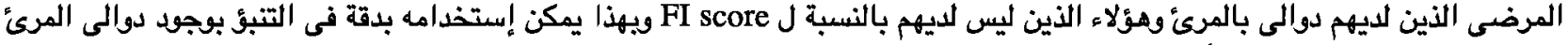

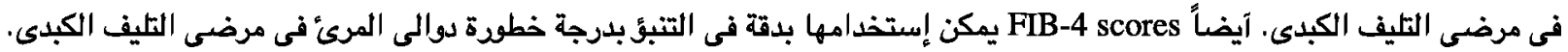

